
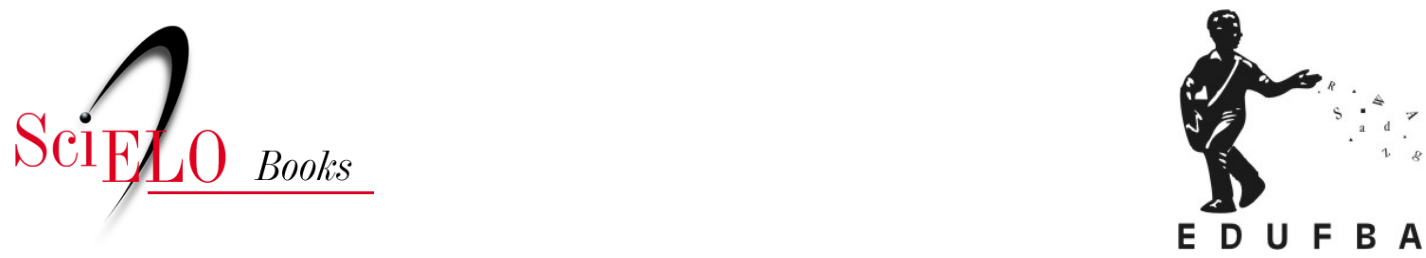

\title{
Capítulo 5 - Curso de formação em segurança alimentar nutricional, abastecimento e mercado institucional
}

\author{
Giovana Paludo Giombelli \\ Rozane Márcia Triches \\ Larissa da Cunha Feio Costa
}

Julian Perrez-Cassarino

Gabriela Arruda Canosa

\section{SciELO Books / SciELO Livros / SciELO Libros}

GIOMBELLI, G. P., PERREZ-CASSARINO, J., TRICHES, R. M., CANOSA, G. A., and COSTA, L. C. F. Curso de formação em segurança alimentar nutricional, abastecimento e mercado institucional. In: CARVALHO, M. C. V. S., CAMPOS, F. M., and KRAEMER, F. B., eds. Tecnologias sociais e de comunicação como recursos educacionais em alimentação [online]. Salvador: EDUFBA, 2020, pp. 133-153. ISBN: 978-65-5630-198-3. http://doi.org/10.7476/9786556301983.0007.

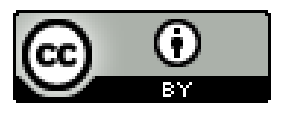

All the contents of this work, except where otherwise noted, is licensed under a Creative Commons Attribution 4.0 International license.

Todo o conteúdo deste trabalho, exceto quando houver ressalva, é publicado sob a licença Creative Commons Atribição 4.0.

Todo el contenido de esta obra, excepto donde se indique lo contrario, está bajo licencia de la licencia Creative Commons Reconocimento 4.0. 


\title{
CURSO DE FORMAÇÃO EM SEGURANÇA ALIMENTAR NUTRICIONAL, ABASTECIMENTO E MERCADO INSTITUCIONAL ${ }^{1}$
}

\author{
GIOVANA PALUDO GIOMBELLI \\ JULIAN PERREZ-CASSARINO \\ ROZANE MÁRCIA TRICHES \\ GABRIELA ARRUDA CANOSA \\ LARISSA DA CUNHA FEIO COSTA
}

\section{INTRODUÇÃO}

O mercado institucional escolar tem sido um dos espaços privilegiados para possibilitar a construção social de mercados alternativos. Países como a Itália, Escócia, Tailândia, Japão, Gana, Nigéria e Estados Unidos têm adotado iniciativas visando aproximar a produção e o consumo de alimentos em âmbito escolar, por meio da compra de alimentos produzidos por agricultores familiares locais. Essas ações são focadas tanto no encurtamento da cadeia produtiva de alimentos, na sustentabilidade e no desenvolvimento rural, como também na aproximação com os hábitos alimentares do local e melhoria da qualidade da refeição servida. (MORGAN; SONINO, 2008; SOARES, 2011; TRICHES; SCHNEIDER, 2010)

No Brasil, esta construção de mercados alternativos é concretizada, principalmente, no Programa Nacional de Alimentação Escolar (PNAE),

1 Texto derivado do projeto intitulado "Agricultura familiar, abastecimento e mercados institucionais: conexões entre Brasil, Cabo Verde e Uruguai na Promoção da Segurança Alimentar e Nutricional". Financiamento: Conselho Nacional de Desenvolvimento Científico e Tecnológico (CNPq). 
considerada uma das políticas alimentares mais antigas. Sua origem, de caráter predominantemente assistencialista, ocorre por volta de 1930, por influência de um grupo de nutrólogos sociais, entre eles Josué de Castro. (MALUF, 2007) Castro "denunciou o silêncio em torno da fome, provocado pelos interesses e preconceitos de ordem moral e de ordem política econômica da civilização ocidental que tornavam a fome de alimentos [...] um tema proibido". (MALUF, 2007, p. 79) Sendo que, em 1954, foi elaborado o Plano Nacional de Alimentação e Nutrição, assumido como política de Estado de grande importância socioeducacional. No entanto, somente em 1979, o Programa passou a denominar-se de PNAE.

Anos depois, em 1988, a alimentação dos escolares de ensino fundamental passa a ser um direito constituído e um dever do Estado. Até 1994, o desenho e gerenciamento do Programa mantiveram centralizado o processo de aquisição de gêneros alimentícios. Devido a interesses da indústria alimentícia, priorizou-se a distribuição de alimentos formulados e industrializados que eram comprados de um conjunto selecionado de empresas, por meio de licitação pública e distribuídos para todo o território nacional.

A consolidação da descentralização ocorreu a partir de 1998, quando a transferência de recursos passou a ser feita automaticamente, sem a necessidade de celebração de convênios ou quaisquer outros instrumentos similares, permitindo maior agilidade ao processo.

Em meados dos anos 2000, o PNAE configura-se fortemente como um programa de Segurança Alimentar e Nutricional (SAN), que visa à garantia de toda a qualidade regular e permanente dos alimentos, sendo em quantidades suficientes, de forma que não comprometa outras necessidades essenciais e que estes alimentos respeitem a diversidade socioambiental. (MALUF, 2007)

Uma das ações para concretizar as proposições de SAN foi a revisão dos programas públicos alimentares, como o Programa Nacional de Alimentação Escolar. Já na Resolução n 15, de 16 de junho de 2003, o objetivo do PNAE passa a ser o de "suprir parcialmente as necessidades nutricionais dos alunos, com vistas a garantir a implantação da política de Segurança Alimentar e contribuir para a formação de bons hábitos alimentares". (BRASIL, 2003, p. 2) 
Em um primeiro momento, houve o aumento de recursos alocados e do público atendido. Mas, acima de tudo, a Resolução n 32, de 2006, promulga entre suas diretrizes o apoio ao desenvolvimento sustentável, além da promoção de alimentação saudável e adequada, a educação alimentar e nutricional. Porém, embora as regulamentações do PNAE no Brasil fizessem alusão à segurança alimentar e ao desenvolvimento sustentável após o processo de descentralização e, mais fortemente, depois da implantação da política de $S A N,{ }^{2}$ o processo de aquisições públicas para o Programa impedia a efetivação dos propósitos de adquirir produtos locais de pequenos produtores.

Para tanto, ponto fundamental nesse processo foi a mudança nos princípios e regulamentos das aquisições públicas, que ocorreu em 2009 com a promulgação da Lei n ${ }^{\circ} 11.947$, em seu Artigo 14, em que há a determinação que "o total dos recursos financeiros repassados pelo Fundo Nacional de Desenvolvimento da Educação (FNDE), no âmbito do PNAE, no mínimo 30\% (trinta por cento) deverão ser utilizados na aquisição de gêneros alimentícios diretamente da agricultura familiar e do empreendedor familiar rural ou de suas organizações”. (BRASIL, 2009, p. 5; CORÁ; BELIK, 2012; REINACH; CORÁ; BONDUKI, 2012; TRICHES; SCHNEIDER, 2012) Essa nova legislação inaugura as tentativas de transformar a retórica em realidade e apoiar efetivamente o propalado desenvolvimento sustentável.

Esta lei surge como potencial reintegrador da cadeia de abastecimento, tendo condições de auxiliar no enfrentamento das problemáticas referentes ao consumo e à produção de alimentos. (CARVALHO, 2008; TRICHES; SCHNEIDER, 2010)

Estudos indicam que a compra de produtos da agricultura familiar para o PNAE tem demonstrado potencialidades no que tange aos consumidores, indicando aumento na disponibilidade e na quantidade de alimentos de qualidade nutricional superior, como frutas, verduras e legumes e a valorização de produtos da cultura alimentar da região, o que provoca mudanças nas práticas alimentares e concepções das crianças. (BELIK; CHAIM, 2009; TRICHES et al., 2010; TURPIN, 2009)

2 Lei no 11.346, de 15 de setembro de 2006. Cria o Sistema Nacional de Segurança Alimentar e Nutricional - SISAN com vistas em assegurar o direito humano à alimentação adequada e dá outras providências. 
Diante da interface entre agricultura e alimentação escolar, a atuação de diferentes agentes sociais surge como parte importante para uma articulação entre os setores. Conforme aponta Soares (2011), a integração de todos os agentes envolvidos na cadeia produtiva de alimentos fornecidos pela agricultura familiar para a alimentação escolar é importante na busca pela garantia da SAN. Para tanto, essa integração deve ocorrer em nível nacional e ser operacionalizada na gestão municipal, que deve atuar na articulação das partes e no desenvolvimento da produção local de alimentos. Com estas prerrogativas e com as novas formas de aquisição pública realizadas pelo PNAE, abrem-se janelas de oportunidades para implementar processos de reconexão entre produtores e consumidores que favoreçam a SAN de ambos. No entanto, se não forem formuladas metodologias que visem fortalecer esses laços e retroalimentar essas relações, a concepção da política se resumirá apenas em mais uma prática de intervenção governamental pontual.

Ou seja, a implementação do Programa, no que se refere à aquisição dos produtos da agricultura familiar, demanda diversas ações e atores para o redesenho das relações sociais, políticas e econômicas no âmbito local e regional, nem sempre muito simples de serem efetivadas.

Por outro lado, estudos recentes (ALTEMBURG, 2014; MOSSMANN et al., 2017) e observações a campo têm demonstrado que a partir do momento que estas engrenagens começam a se encaixar, os resultados se mostram extremamente favoráveis e o fornecimento de refeições aos escolares passam a assumir uma nova dimensão, tornando-se meios para a problematização dos processos educacionais e para o desenvolvimento local e regional.

Compreender essas dinâmicas torna-se um elemento central para a plena execução do PNAE e, nesse sentido, identificar os formatos institucionais construídos nas mais diversas realidades pode possibilitar a sistematização de informações que qualifiquem e ampliem a implementação do Programa, garantindo que este cumpra seu objetivo primordial de promoção da SAN.

Contudo, no Brasil ainda são escassos estudos e intervenções que abordam e reforçam o papel deste Programa como política pública que pode construir essas interfaces. Diante dessas prerrogativas é que se torna 
importante elaborar metodologias para a construção de redes de cooperação técnica que subsidiem e incentivem estes processos. Da mesma forma, avaliar e sistematizar mecanismos sociais e econômicos que possibilitem a (re)estruturação de circuitos locais e regionais de abastecimento, buscando compreender de que forma a articulação em torno do programa de alimentação escolar promove laços que agregam diferentes atores sociais e favorecem a promoção de modelos de desenvolvimento mais sustentáveis.

Diante do exposto, explana-se que este estudo fez parte de um projeto maior intitulado "Agricultura familiar, abastecimento e mercados institucionais: conexões entre Brasil, Cabo Verde e Uruguai na Promoção da Segurança Alimentar e Nutricional", ${ }^{3}$ desenvolvido entre 2013 e 2016. Este tinha por objetivo geral construir redes de cooperação técnica capazes de articular o consumo e a produção de alimentos, com foco no mercado institucional de alimentação escolar, como intuito de promover alimentação adequada e saudável e a construção de sistemas agroalimentares sustentáveis nos estados do Paraná (PR), Santa Catarina (SC) e Rio Grande do Sul (RS) em diálogo com experiências e estudos dos países de Cabo Verde e Uruguai.

\section{METODOLOGIA}

Para o desenvolvimento deste projeto, foi utilizado a metodologia centrada nos marcos da chamada Pesquisa-ação. (THIOLLENT, 2006) A compreensão da realidade a ser pesquisada parte do conhecimento mútuo entre os atores envolvidos - pesquisadores e atores locais -, de modo que desde o princípio das ações do projeto procurou-se estabelecer uma dinâmica participativa de identificação das demandas e ações a serem desenvolvidas, dentro da temática proposta como escopo do projeto.

A pesquisa-ação parte do pressuposto de um compartilhamento das informações entre os atores locais e os autores (pesquisadores), caminhando no sentido de uma interação entre os dois de forma que um possa, à

3 Chamada MCTI/Ação Transversal - Lei no 82/2013 - Segurança Alimentar e Nutricional no Âmbito da Unasule África. Financiado pelo Conselho Nacional de Desenvolvimento Científico e Tecnológico (CNPq). 
sua maneira, cumprir também o papel do outro, atores tornando-se pesquisadores e vice-versa.

Foi nessa perspectiva que foram desenhadas as ações deste projeto, no intuito de mesclar a compreensão da realidade em voga, particularmente no que tange aos processos de aquisição dos produtos da agricultura familiar no âmbito do PNAE, com ações concretas que visam a problematização e qualificação dos processos em questão.

Este projeto, por sua vez, apresentava diversos objetivos específicos: realizar um diagnóstico sobre a implementação do PNAE nos três estados do Sul, identificando o atendimento à exigência de aquisição de produtos da agricultura familiar e afins; identificar os mecanismos de acesso construídos por parte das organizações de agricultores e Entidades Executoras (EEx); mapear a presença de produtos ecológicos no fornecimento do PNAE; promover seminários e encontros estaduais para divulgação e troca de experiências entre organizações de agricultores e consumidores, escolas, Conselhos de Alimentação Escolar (CAEs), EEx e demais atores envolvidos no processo, a fim de qualificar os processos de acesso ao PNAE; realizar intercâmbios entre Brasil, Cabo Verde e Uruguai para troca de experiências entre os países, a partir de atividades de pesquisa, extensão e ensino em formas alternativas de abastecimento e visando a construção de propostas comuns de abertura e ajustes do mercado institucional para a agricultura familiar.

E por fim, a partir desses objetivos, foi possível realizar a construção de redes virtuais de atores que promovam atividades de intercâmbio, formação, publicidade, articulação e sistematização de metodologias que abordem as formas alternativas de abastecimento no âmbito da agroecologia, bem como os processos de educação alimentar dos escolares e de adaptação dos agricultores familiares ao mercado do PNAE, a qual trata-se este manuscrito.

Assim, para que este objetivo pudesse ser realizado, foram promovidos, em 2015, três seminários estaduais nos três estados do Sul (PR, SC, RS) para formação e intercâmbio de experiências entre os diversos atores envolvidos no processo, bem como com os parceiros internacionais, como mecanismo inicial de articulação de redes ou fóruns microrregionais de SAN a partir do debate em torno do abastecimento e alimentação escolar. 
Destes seminários estaduais saíram diversas demandas que deram subsídio para a construção e seleção dos conteúdos para idealizar o curso de Educação a Distância (EaD). Os principais eixos de demanda foram o funcionamento da política do PNAE, o contexto da produção ecológica, a educação alimentar e nutricional (EAN) e, principalmente, o envolvimento e articulação de diferentes atores dentro do Programa. Desta forma, considerou-se para este curso os seguintes atores sociais envolvidos com o PNAE: os gestores públicos que gerenciam a aquisição dos produtos da $\mathrm{AF}$ (nutricionistas, secretária da educação e/ou agricultura), os Agricultores Familiares (AF) responsáveis pela oferta de produtos, extensionistas - Empresa de Assistência Técnica e Extensão Rural (Emater), Empresa de Pesquisa Agropecuária e Extensão Rural de Santa Catarina (Epagri), entre outros - como aporte técnico aos agricultores, Conselheiros de Alimentação Escolar (CAE) que realizam o processo de fiscalização do PNAE e conselheiros de segurança alimentar e nutricional (Consea).

A partir desses eixos temáticos, o curso EaD foi desenvolvido pelo Núcleo de Estudos Avançados em Soberania e Segurança Alimentar e Nutricional - Karu-Porã (NEA-SSAN Karu Porã), da Universidade Federal da Fronteira Sul (UFFS), Campus Laranjeiras do Sul - Paraná, utilizando a plataforma Moodle, para disponibilizar os materiais. O curso foi intitulado "Formação em Segurança Alimentar e Nutricional: abastecimento, agricultura familiar e alimentação escolar”.

Foram ofertadas inicialmente 80 vagas (divididas 20 vagas para cada estado do Sul - PR, SC, RS e 20 vagas para o restante do país -; turma única. Inscreveram-se mais de 2 mil pessoas. Como critérios de seleção dos estudantes consideraram-se as categorias de atores (nutricionistas, extensionistas, agricultores, Consea, gestores públicos, CAE, outros), tempo de atuação na profissão e o breve histórico que cada um registrou na ficha de inscrição on-line. Em vista do grande número de inscritos e o número de moderadores, ofertou-se mais 22 vagas. Ressalta-se que a divulgação do curso ocorreu no Uruguai e Cabo Verde, com os parceiros do projeto. Ao final, 102 estudantes foram selecionados e divididos dentro das categorias de atores, como apresenta o Quadro 1: 
Quadro 1: Atores selecionados por categorias e estados

\begin{tabular}{|l|c|c|c|c|c|}
\hline ATORES & $\begin{array}{c}\text { RIO GRANDE } \\
\text { DO SUL }\end{array}$ & SANTA CATARINA & PARANÁ & OUTROS ESTADOS & $\begin{array}{c}\text { ESTRANGEIROS } \\
\text { (URUGUAI, CABO VERDE) }\end{array}$ \\
\hline Agricultores & 2 & 2 & 3 & 1 & - \\
\hline CAE & 1 & 1 & 1 & - & - \\
\hline Consea & 2 & 2 & 2 & 3 & - \\
\hline Extensionista & 3 & 3 & 3 & 13 & - \\
\hline Gestores públicos & 2 & 1 & 4 & 15 & 5 \\
\hline Nutricionistas & 14 & 14 & 1 & 19 & 5 \\
\hline Outros & 1 & 24 & 29 & 102 estudantes \\
\hline Total por região & 25 & &
\end{tabular}

Fonte: elaborado pelos autores.

Esta seleção foi muito minuciosa, devido ao grande número de inscritos. Cabe destacar que a divisão por atores, nos estados de PR, SC e RS, ficou com 25 participantes para cada um dos estados. Destas vagas dividiram-se 14 nutricionistas, 3 extensionistas, 2 agricultores, 2 Consea, 2 gestores públicos, $1 \mathrm{CAE}$, e 1 outros (estudantes que não estava nestas categorias de atores). Quanto a outros estados, estavam destinadas 20 vagas, sendo 15 para nutricionistas, 1 extensionistas, 1 agricultor, 1 Consea, 1 gestor público e $1 \mathrm{CAE}$. E para estrangeiros estavam destinadas 5 vagas. Ao final, algumas categorias de atores não completaram o número de inscritos, portanto foram recondicionadas vagas para outras categorias que tinham mais inscritos, mesmo sendo de outros estados.

Outro ponto a ser considerado é justificar o porquê de algumas categorias de atores terem mais vagas que as outras. A princípio este curso $\mathrm{EaD}$ seria apenas para nutricionistas, considerando que os mesmos possuem um papel fundamental no PNAE. Mas para que eles possam desenvolver um papel efetivo dependem de muitas parcerias, desta forma abriram-se outras vagas para estes atores centrais que contribuem para o processo da aquisição de produtos.

O curso foi iniciado em 04/07/2016 e concluído em 19/12/2016 (duração de seis meses). A elaboração/seleção do conteúdo e metodologia do curso ficou a cargo de dois professores do Programa de Pós-Graduação em Agroecologia e Desenvolvimento Rural Sustentável (Mestrado) da 
Universidade Federal da Fronteira Sul (UFFS), duas estudantes do mestrado e por uma nutricionista voluntária. Quanto à correção das atividades e a mediação dos fóruns dos módulos, ficaram a cargo das estudantes de mestrado e da nutricionista voluntária.

O curso foi dividido em 10 etapas, sendo cada uma de duas semanas. Para cada módulo foi disponibilizada ao menos uma videoaula de 30 a 50 minutos com colaboradores externos que abordaram os temas propostos, incluindo ainda material obrigatório para leitura e material de apoio para maior aprofundamento sobre a temática, e ao final um estudo dirigido referente ao módulo. Durante essas duas semanas ocorriam fórum de debates on-line e off-line, ou seja, um espaço para o intercâmbio de informações entre os moderadores e participantes. Os debates on-line eram ofertados um dia dentro de cada módulo, onde um moderador ficava responsável por responder aos questionamentos, bem como proporcionar um momento dos estudantes interagirem entre si. E o fórum off-line ocorria conforme surgiam às dúvidas dos estudantes. Ressalta-se que nestes fóruns off-line os próprios estudantes realizam avaliações referentes aos módulos, destacando o quanto relevante o mesmo era. Entre o módulo IX e o módulo X, foram deixadas duas semanas para quem tivesse atividades atrasadas finalizar. Os módulos ofertados apresentaram as seguintes temáticas e objetivos, como ilustra o Quadro 2:

Quadro 2: Módulos ofertados no curso EaD, 2016

\begin{tabular}{|l|l|l|l|}
\hline MÓDULOS & VÍ́EO & MATERIAL OBRIGATÓRIO & MATERIAL DE APOIO \\
\hline Módulo I - Princípios da & Apresentado por Renato & - Perez-Cassarino, et al., & - Belik, 2003 \\
SAN, abastecimento e & Maluf ${ }^{4}$ & - Sisan, 2010 \\
Mercados Institucionais & & - Rigon e Bógus, 2015 & - Consea, 2006/ 2009 \\
& - Triches e Bacarrin, 2016 & - Júnior, 2007 \\
& - Macedo et al., 2009 \\
\hline
\end{tabular}

4 Renato Maluf: Professor Titular do Departamento de Desenvolvimento, Agricultura e Sociedade (DDAS) e membro permanente do Programa de Pós-Graduação de Ciências Sociais em Desenvolvimento, Agricultura e Sociedade (CPDA), da Universidade Federal Rural do Rio de Janeiro (UFRRJ). Coordenador do CERESAN/UFRRJ, e integrante do Observatório de Políticas Públicas para a Agricultura (OPPA). Integrante da Chaire Unesco. Membro da Coordenação Nacional do Fórum Brasileiro de Segurança Alimentar e Nutricional. Coordenador da Rede Brasileira de Pesquisa em Soberania e Segurança Alimentar e Nutricional, 2017/19. 


\begin{tabular}{|c|c|c|c|}
\hline MÓDULOS & VÍDEO & MATERIAL OBRIGATÓRIO & MATERIAL DE APOIO \\
\hline $\begin{array}{l}\text { Módulo II - Elaboração de } \\
\text { chamadas }\end{array}$ & $\begin{array}{l}\text { Apresentado por Sara } \\
\text { Regina Souto Lopes }\end{array}$ & $\begin{array}{l}\text { - Bacarrin et al., } 2011 \\
\text { - Triches, } 2015\end{array}$ & $\begin{array}{l}\text { - FNDE RESOLUÇÃO } \\
\text { n 26/2013 } \\
\text { - Santana et al., } 2015 \\
\text { - SEBRAE } \\
\text { - Aguiar e Calil, } 2016 \\
\text { - Lei } 8.666 / 1993 \\
\text { - Lei 11.947/2009 } \\
\text { - Lei 12.188/2010 }\end{array}$ \\
\hline \multicolumn{4}{|c|}{$\begin{array}{l}\text { Objetivo: Apresentar o que é uma chamada pública, como a mesma é planejada e executada, e principalmente os } \\
\text { estudantes aprender a fazer uma chamada pública. }\end{array}$} \\
\hline $\begin{array}{l}\text { Módulo III - Elaboração e } \\
\text { gestão de projetos }\end{array}$ & $\begin{array}{l}\text { Apresentado por José } \\
\text { Antonio da Silva Marfil }\end{array}$ & $\begin{array}{l}\text { - SEBRAE } 2014 \\
\text { - Silva, Dias, Júnior, } 2015\end{array}$ & $\begin{array}{l}\text { - Modelos de contrato de } \\
\text { compras }\end{array}$ \\
\hline \multicolumn{4}{|c|}{$\begin{array}{l}\text { Objetivo: Conhecer a realidade local dos projetos de venda dos agricultores e aprimorar seus conhecimentos com novas } \\
\text { possibilidades na elaboração e gestão de projetos para o PNAE. }\end{array}$} \\
\hline $\begin{array}{l}\text { Módulo IV - Planejamento } \\
\text { de produção e produção } \\
\text { ecológica (agricultores) }\end{array}$ & $\begin{array}{l}\text { Apresentado por } \\
\text { Rubens Fey }\end{array}$ & $\begin{array}{l}\text { - Perez-Cassarino et al., } \\
2013\end{array}$ & - PROGERA, 2009 \\
\hline \multicolumn{4}{|c|}{$\begin{array}{l}\text { Objetivo: Realizar um projeto de venda para a chamada pública, embasado nos matériais deste módulo e dos módulos } \\
\text { anteriores. }\end{array}$} \\
\hline $\begin{array}{l}\text { Módulo V - Educação } \\
\text { alimentar e nutricional } \\
\text { (EAN) }\end{array}$ & $\begin{array}{l}\text { Apresentado por } \\
\text { Neila Maria Machado e } \\
\text { Élister L. B. Balestrin }{ }^{9}\end{array}$ & $\begin{array}{l}\text { - Boog, } 2004 \\
\text { - Triches, } 2015\end{array}$ & $\begin{array}{l}\text { - Guia alimentar para } \\
\text { a população brasileira } \\
\text { (BRASIL, 2014) }\end{array}$ \\
\hline \multicolumn{4}{|c|}{$\begin{array}{l}\text { Objetivo: Traçar um planejamento de atividades em EAN no ambiente escolar a ser desenvolvido em um ano, e quando } \\
\text { possível aplicá-lo. }\end{array}$} \\
\hline $\begin{array}{l}\text { Módulo VI - Formulação de } \\
\text { cardápios }\end{array}$ & $\begin{array}{l}\text { Apresentado por } \\
\text { Rozane Márcia Triches }{ }^{10} \text { e } \\
\text { Élister L. B. Balestin }\end{array}$ & $\begin{array}{l}\text { - Gabriel et al., } 2012 \\
\text { - Sousa et al., } 2015\end{array}$ & - Santos et al., 2015 \\
\hline \multicolumn{4}{|c|}{$\begin{array}{l}\text { Objetivo: Apresentar um cardápio elaborado para um município X, onde os estudantes avaliassem se o mesmo atende a } \\
\text { dimensão nutricional, cultural, social e ambiental. }\end{array}$} \\
\hline
\end{tabular}

5 Sara Regina Souto Lopes: Trabalha no Fundo Nacional de Desenvolvimento da Educação (FNDE). Atua na Coordenação de Planejamento da Diretoria Financeira do FNDE.

6 José Antonio da Silva Marfil: Produtor agroecológico de Bocaiúva do Sul - PR.

7 Rubens Fey: Professor da Universidade Federal da Fronteira Sul (UFFS), Campus Laranjeiras do Sul - PR.

8 Neila Maria Machado: Professora da Universidade Federal de Santa Catarina (UFSC). Participa do Grupo de Pesquisa TearSAN - Teia de Articulação pelo Fortalecimento da Segurança Alimentar e Nutricional.

9 Élister L. B. Balestin: nutricionista da alimentação escolar no município de Capitão Leonidas Marques - PR.

10 Rozane Márcia Triches: Professora do Curso de Graduação em Nutrição e da Pós-Graduação Stricto Sensu em Agroecologia e Desenvolvimento Rural Sustentável da Universidade Federal da Fronteira Sul 


\begin{tabular}{|c|c|c|c|}
\hline MódULOS & VÍDEO & MATERIAL OBRIGATÓRIO & MATERIAL DE APOIO \\
\hline $\begin{array}{l}\text { Módulo VII - Receitas e } \\
\text { preparo de alimentos }\end{array}$ & $\begin{array}{l}\text { Apresentado por Amanda } \\
\text { Marfil }{ }^{11}\end{array}$ & - Marfil, 2014 & - \\
\hline \multicolumn{4}{|c|}{$\begin{array}{l}\text { Objetivo: Elaborar um treinamento para as cozinheiras das escolas, contendo receitas a serem inseridas no cardápio } \\
\text { das escolas em seus respectivos municípios. }\end{array}$} \\
\hline $\begin{array}{l}\text { Módulo VIII - Qualidade } \\
\text { dos alimentos (Conceito e } \\
\text { vigilância sanitária) }\end{array}$ & $\begin{array}{l}\text { Apresentado por } \\
\text { Fabiana Thomé da Cruz }\end{array}$ & - Cruz e Santos, 2016 & - \\
\hline \multicolumn{4}{|c|}{$\begin{array}{l}\text { Objetivo: Interpretar as leis da vigilância sanitária em situações reais do dia a dia, como quais os procedimentos a } \\
\text { serem providenciados para um agricultor familiar poder regularizar uma agroindústria de laticínios. }\end{array}$} \\
\hline $\begin{array}{l}\text { Módulo IX - Participação e } \\
\text { controle social do PNAE. }\end{array}$ & - & $\begin{array}{l}\text { - Pipitone, } 2003 \\
\text { - FNDE, } 2015 \\
\text { - Triches e Kilian, } 2016\end{array}$ & - Belik e Chaim, 2009 \\
\hline \multicolumn{4}{|c|}{$\begin{array}{l}\text { Objetivo: Conhecer o funcionamento do Conselho de Alimentação Escolar (CAE) do município e criar um plano de ação } \\
\text { para ajudar a qualificar o Conselho. }\end{array}$} \\
\hline $\begin{array}{l}\text { Módulo X - Etapa Bônus: } \\
\text { Experiências internacionais } \\
\text { e nacionais de } \\
\text { abastecimento alimentar, } \\
\text { alimentação. }\end{array}$ & \multicolumn{3}{|c|}{$\begin{array}{l}\text { - Videoaula: Experiência de abastecimento alimentar e alimentação escolar em Cabo } \\
\text { Verde. Apresentado por Vladmir F. Perreira. }{ }^{13} \\
\text { - Vídeos de experiências brasileiras sobre o PNAE: PNAE em Erechim - Programa Rio } \\
\text { Grande Rural/ PNAE de Messias/AL é destaque no Gazeta Rural/ Prefeitura de São Luís } \\
\text { - PNAE: Alimentação Escolar Reforçada - Documentário/ Programa de Merenda Escolar } \\
\text { Teodoro Sampaio - SP/ Alimentação Escolar - } 1^{0} \text { Bloco/ Alimentação Escolar - } \\
2^{0} \text { Bloco/ Alimentação Escolar - } 3^{0} \text { Bloco/ Antes \& Depois da Lei \#65 - Lei Merenda } \\
\text { Escolar/ Videoaula: A realidade brasileira de abastecimento alimentar. }\end{array}$} \\
\hline
\end{tabular}

Fonte: elaborado pelos autores.

Após o dia 19/12/2016, foi realizada a avaliação de cada estudante, para saber se todas as atividades propostas haviam sido realizadas para poder receber a certificação. Os estudantes que realizaram mais de 75\% das tarefas receberam certificado de 72 horas do curso, emitido pelo Sistema de Gestão de Certificados Eletrônicos (SGCE) da UFFS.

11 Amanda Marfil: Produtora agroecológica de Bocaiuva do Sul - PR.

12 Fabiana Thomé da Cruz: Professora colaboradora no Programa de Pós-Graduação em Desenvolvimento (PGDR/UFRGS).

13 Vladmir F. Perreira: Professor da Escola Superior de Ciências Agrárias e Ambientais Universidade de Cabo Verde. 


\section{RESULTADOS E DISCUSSÃO}

O impulso proporcionado pelo curso EaD foi fundamental, pois possibilitou beneficiar diretamente 102 pessoas com as atividades do projeto, tendo como público participante Conselheiros do CAE e Consea, nutricionistas, agricultores, técnicos de extensão, entre outros. Este público abrangeu todo o território nacional, Uruguai e Cabo Verde, sendo uma troca de experiências valiosa. Exemplos desta troca destacam-se no módulo II, sobre a elaboração de chamadas públicas os estudantes no chat iniciaram diversos debates referentes às compras da agricultura familiar, exigências de qualidade e padronização dos alimentos, mas tendo destaque principal a temática referente à terceirização da alimentação escolar. Um dos estudantes ${ }^{14}$ destaca que:

Sabemos que as empresas terceirizadas não realizam a compra dos produtos oriundos da Agricultura Familiar (pelo menos a grande maioria), beneficiam apenas empresas de grande porte, desvalorizando o produtor local. Além disso, não temos como garantir a qualidade nutricional e segurança alimentar das refeições ofertadas aos escolares. Sou contra a terceirização, pois a mesma impossibilita o desenvolvimento do produtor familiar local, não visa à sustentabilidade eàs vezes não respeita a cultura alimentar da região. (Estudante 1)

Nesta discussão observou-se a necessidade de mais estudos referentes à terceirização da alimentação escolar e suas limitações quanto à aquisição de produtos da agricultura familiar.

Outrossim, destaca-se a importância dos materiais fornecidos (videoaulas, artigos, cartilhas etc) por terem uma linguagem clara a todos os estudantes, como demonstra um estudante no chat do módulo $\mathrm{V}$ referente a EAN:

Não possuo grande vivência neste módulo, principalmente por meu currículo escolar, fizemos agronomia, e acredito que este enfoque seja

14 O projeto passou pelo comitê de ética da UFFS. 
muito pouco abordado, porém a palestra sobre o tema na Vídeo Aula e experiência relatadas foram para mim muito esclarecedoras e motivadoras. Parabéns. O material de apoio também está nos auxiliando é muito bom. (Estudante 2)

Em diversas situações destacou-se a importância do chat para a troca de experiências entre países. No módulo VII -formulação de cardápios-, ocorreu uma discussão referente à inclusão ou não na comida de panela nos lanches das escolas. Os estudantes foram apresentando o que ocorria em seu município, e um dos estudantes estrangeiros destacou a importância dessa troca de experiência:

Estou gostando muito deste curso, é excelente para troca de experiência, principalmente entre países. Deu para perceber que a realidade de cada região, influencia na tomada de decisões, principalmente no cardápio a ser elaborado. E no nosso país ocorre a mesma situação. Existe aqui em Cabo verde, algumas escolas com alunos carentes, na qual a comida da escola é a única refeição do dia. Assim optou-se por colocar comida de panela no cardápio anual que é elaborado pela nutricionista do PNAE. Mesmo sabendo que nos lanches não é adequado este tipo de refeição, na nossa realidade é muito mais difícil planejar o cardápio sem comida de panela. (Estudante 3)

Vislumbra-se que mesmo as atividades sendo realizadas virtualmente, o chat de bate-papo contribuiu para troca de experiências e também para tirar dúvidas entre os estudantes.

Por outro lado, de forma indireta, acreditamos que estes participantes possam ser perpetuadores desse conhecimento adquirido e atingir novos indivíduos em seus ambientes de trabalho, sejam os conselhos, sejam as escolas ou instâncias públicas.

Destaca-se, do ponto de vista acadêmico, que o projeto possibilitou um avanço significativo na formação dos acadêmicos envolvidos como voluntários do projeto. Este contato levou a maturidade, conhecimento de diferentes realidades e possibilidade de aplicação de conteúdos das videoaulas à realidade. 
Por outro lado, também foi possível observar um conjunto de fragilidades no processo. Em primeiro lugar, em relação aos cursistas, apesar do surpreendente número de inscritos e das tensões ao selecionar os escolhidos para fazer o curso, muitos cursistas não se dedicaram devidamente, atrasando envio de atividades e alguns chegaram a desistir e não foram certificados. Para tanto, recomenda-se a outras iniciativas a criação de um cadastro de reserva, que permita substituir cursistas menos comprometidos.

Este processo também demonstra a fragilidade do processo de $\mathrm{EaD}$, que, apesar de ampliar consideravelmente o alcance dos processos de formação, não substitui o compromisso e a didática da formação presencial.

Ainda do ponto de vista dos limites, a questão da monitoria foi considerada como uma das mais relevantes no decorrer do curso, mas que se viu prejudicada nesta proposta pelo desejo da organização de ampliar o número de vagas, comprometendo a qualidade do processo de monitoria, refletido no pouco envolvimento de alguns cursistas, e a fragilidade no cumprimento de prazos em relação às tarefas de cada módulo.

Da mesma forma, o NEA possuía uma intenção inicial de capacitar estudantes que viessem se tornar futuros monitores, mas que ainda não se efetivou.

Dentro desta perspectiva, vislumbra-se ainda a construção de uma rede de instituições de ensino superior que fomente a pesquisa, a extensão e o ensino sobre SAN, com foco em formas alternativas de abastecimento dos mercados institucionais do país e em países africanos e latino-americanos.

Nesse sentido, entende-se como frágeis e mal pensadas a maioria das políticas para realização de cursos de $\mathrm{EaD}$, que compreendem que a organização e disponibilização de materiais didáticos e a presença de uma boa plataforma virtual sejam suficientes. Pelo contrário, mesmo sendo $\mathrm{EaD}$, o processo prescinde de recursos humanos e, neste caso, a monitoria das etapas.

Outrossim, foi a disponibilização de subsídios à comunidade científica e aos gestores dos municípios brasileiros, cabo-verdianos e uruguaios para a melhoria da articulação entre PNAE e agricultura familiar, com foco na SAN, em especial na oferta de refeições de qualidade, como por exemplo, indicadores que auxiliem na programação das compras da agricultura familiar e na elaboração de cardápios integrados à produção de alimentos. 
Ao mesmo tempo, possibilitou o fortalecimento de políticas públicas voltadas à alimentação escolar e agricultura familiar, principalmente na melhoria da qualidade das refeições servidas e no desenvolvimento local.

E por fim, vale destacar, que por não possuir mais verbas, foi impossibilitada a continuidade e ampliação do curso, que na época possuía uma grande procura.

\section{CONSIDERAÇÕES FINAIS}

O curso em EaD com Formação em Segurança Alimentar e Nutricional: abastecimento, agricultura familiar e alimentação escolar mostrou um grande potencial a ser explorado. Muitos inscritos que não foram selecionados destacavam nas redes sociais o quanto gostariam de participar, devido à carência de cursos que se apresentem neste formato, pois facilita para muitos que não podem participar de um curso presencial.

Por outro lado, observa-se a necessidade de engrenar ações mais diretas para entender a rede de articulações que formam os mercados institucionais, a segurança alimentar e nutricional, a agricultura familiar e a alimentação escolar. E principalmente construir mais redes virtuais de atores que promovam atividades de intercâmbio, formação, publicidade, articulação e sistematização de metodologias que abordem as formas alternativas de abastecimento no âmbito da agroecologia, bem como os processos de educação alimentar dos escolares e de adaptação dos agricultores familiares ao mercado do PNAE.

Além disso, destaca-se a importância desta parceria sul-sul com países africanos e latino-americanos em promover a construção de sociedades mais justas, igualitárias e sustentáveis. Este curso EaD entra na dinâmica prevista na sétima diretriz do Plano de SAN (2011), que é voltada para a ampliação de ações de cooperação internacional, para ampliar e qualificar iniciativas de intercâmbio de boas práticas referentes aos programas voltados para a Agricultura Familiar, PNAE, entre outros.

Por fim, sem dúvida, o NEA-SSAN Karu Porã se tornou uma referência para o debate da SAN e mercados institucionais, o que demanda a elaboração de um programa de ensino/pesquisa/extensão amplo neste campo. 
De qualquer forma, mesmo o NEA-SSAN tendo tomado um protagonismo, não foi possível no âmbito do Núcleo manter uma articulação mais intensa e duradoura com os parceiros internacionais e nacionais. Sua atividade terminou ficando mais concentrada na própria UFFS, que tem feito um esforço de ampliar sua articulação, mas que, sem apoios específicos para tal, são difíceis de serem conduzidos com recursos das próprias organizações. No momento, por exemplo, o NEA-SSAN Karu Porã executa uma pesquisa nacional sobre orgânicos no PNAE, em parceria com outras 5 universidades e institutos de pesquisa, mas que foi possível devido a presença de recursos que viabilizassem a pesquisa.

Por fim, falando da temática especificamente, há ainda correções a serem feitas, notadamente no caráter mais "sulista" que os materiais possuem, seja pela necessidade de redução de custos em sua produção, seja pelos contatos e conhecimento que os organizadores têm nesta realidade.

Estas questões estão longe de nos levar a uma avaliação negativa ou pessimista, mas embebe de realidade um processo que de pontual poderia ser tornado contínuo.

\section{REFERÊNCIAS}

AGUIAR, J. A.; CALIL, R. M. Análise e avaliação das especificações dos alimentos contidas em editais de chamadas públicas do PNAE. Visa em debate, Rio de Janeiro, v. 4, n. 2, p. 79-87, 2016.

ALTEMBURG, S. G. N. A comida invisível: representações sociais sobre a alimentação escolar entre a comunidade escolar e os agricultores familiares na região de Pelotas, RS. 2014. Tese (Doutorado em Agronomia) - Faculdade de Agronomia Eliseu Maciel, Universidade Federal de Pelotas, Pelotas, 2014.

BACCARIN, J. G.; ALEIXO, S. S.; SILVA, D. B. P. et al. Alimentação escolar e agricultura familiar: alcance e dificuldades para implantação do artigo $14 \mathrm{da}$ Lei 11.947/2009 no estado de São Paulo. In: CONGRESSO DA SOCIEDADE DE ECONOMIA, ADMINISTRAÇÃO E SOCIOLOGIA RURAL, 49., 2011, Belo Horizonte. Anais [...]. Belo Horizonte: SOBER, 2011.

BELIK, W. Perspectivas para segurança alimentar e nutricional no Brasil. Saúde e Sociedade, São Paulo, v. 12, n. 1, p. 12-20, 2003. 
BELIK, W.; CHAIM, N. A. O programa nacional de alimentação escolar e a gestão municipal: eficiência administrativa, controle social e desenvolvimento local. Revista de Nutrição, Campinas, v. 22, n. 5, p. 595-607, 2009.

BOOG, M. C. F. Contribuições da Educação Nutricional à Construção da Segurança Alimentar. Saúde em Revista, Piracicaba, v. 6, n. 13, p. 17-23, 2004.

BRASIL. Câmara Interministerial de Segurança Alimentar e Nutricional. Plano nacional de segurança alimentar e nutricional: 2012/2015. Brasília, DF: CAISAN, 2011.

BRASIL. Lei no 11.947, de 16 de junho de 2009. Dispõe sobre o atendimento da alimentação escolar e do Programa Dinheiro Direto na Escola aos alunos da educação básica; altera as Leis nos 10.880 , de 9 de junho de 2004, 11.273, de 6 de fevereiro de 2006, 11.507, de 20 de julho de 2007; revoga dispositivos da Medida

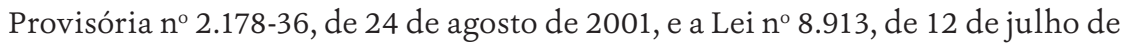
1994; e dá outras providências. Diário Oficial da União: seção 1, Brasília, DF, 17 jun. 2009. Disponível em: http://www.fnde.gov.br/fnde/legislacao/leis/item/3345lei-n\%C2\%BA-11947-de-16-ejunho-de-2009. Acesso em: 15 jun. 2013.

BRASIL. Lei no 12.188, de 11 de janeiro de 2010. Institui a Política Nacional de Assistência Técnica e Extensão Rural para a Agricultura Familiar e Reforma Agrária - PNATER e o Programa Nacional de Assistência Técnica e Extensão Rural na Agricultura Familiar e na Reforma Agrária - PRONATER, altera a Lei no 8.666, de 21 de junho de 1993, e dá outras providências. Diário Oficial da União: seção 1, Brasília, DF, 12 jan. 2010. Disponível em: http://www.planalto.gov.br/ccivil_03/_ Ato2007-2010/2010/Lei/L12188.htm. Acesso em: 10 jun. 2019.

BRASIL. Lei n 8.666, de 21 de junho de 1993. Regulamenta o art. 37, inciso XXI, da Constituição Federal, institui normas para licitações e contratos da Administração Pública e dá outras providências. Diário Oficial da União: seção 1, Brasília, DF, 6 jul. 1993. Disponível em: http://www.planalto.gov.br/ccivil_03/leis/18666cons. htm. Acesso em: 10 jun. 2019.

BRASIL. Ministério da Educação. Cartilha nacional da alimentação escolar. 2. ed. Brasília, DF: Ministério da Educação: 2015.

BRASIL. Ministério da Saúde. Guia alimentar para a população brasileira. 2. ed. Brasília, DF: Ministério da Saúde, 2014. 
BRASIL. Resolução n 15, de 16 de junho de 2003. Estabelecer critérios para o repasse de recursos financeiros, à conta do PNAE, previstos na Medida Provisória $\mathrm{n}^{\circ}$ 2.178-36, de 24 de agosto de 2001. Diário Oficial da União, Brasília, DF, 17 jun. 2003. Disponível em: https://www.fnde.gov.br/index.php/acesso-a-informacao/ institucional/legislacao/item/4272-resolu\%C3\%A7\%C3\%A3o-cd-fnde-n\%C2\%BA15,-de-16-de-junho-de-2003. Acesso em: 25 ago. 2020.

BRASIL. Resolução n 26, de 17 de junho de 2013. Dispõe sobre o atendimento da alimentação escolar aos alunos da educação básica no âmbito do Programa Nacional de Alimentação Escolar - PNAE. Diário Oficial da União, Brasília, DF, 18 jun. 2013.

BRASIL. Resolução ${ }^{\circ}$ 32, de 10 de agosto de 2006. Estabelecer as normas para a execução do Programa Nacional de Alimentação Escolar - PNAE. Diário Oficial da União, Brasília, DF, 11 ago. 2006.

CARVALHO, D. G. Licitações sustentáveis, alimentação escolar e desenvolvimento regional: uma discussão sobre o poder de compra governamental a favor $\mathrm{da}$ sustentabilidade. Planejamento e políticas públicas, Brasília, DF, n. 32, p. 115, 148, 2008.

CARVALHO, H. M. Modelo de produção agrária no Brasil. In: SEMINÁRIO DE ENFRENTAMENTO AOS IMPACTOS DOS AGROTÓXICOS NA SAÚDE HUMANA E NO AMBIENTE, 1., 2012, Rio de janeiro. Anais [...]. Rio de janeiro: Fiocruz, 2012.

CONSELHO NACIONAL DE SEGURANÇA ALIMENTAR E NUTRICIONAL. Construção do sistema e da política nacional de segurança alimentar e nutricional: a experiência brasileira. Brasília, DF: CONSEA, 2009.

CONSELHO NACIONAL DE SEGURANÇA ALIMENTAR E NUTRICIONAL. Lei de segurança alimentar e nutricional: lei no 11.346, de 15 de setembro de 2006. [S. l.]: Consea, [20--].

CORÁ, M. A. J.; BELIK, W. Ministério do Desenvolvimento Agrário. Projeto Nutre $S P$ : análise da inclusão da agricultura familiar na alimentação escolar no estado de São Paulo. São Paulo: Instituto Via Pública, 2012.

CRUZ, F. T.; SANTOS, J. S.; SARTORELLI, A. et al. Guia orientador para agroindústrias: regulamentos, legalização e inspeção de alimentos no Brasil. Porto Alegre: [s. n.], 2016.

GABRIEL, C. G.; COSTA, L. C. F.; CALVO, M. C. M. et al. Planejamento de cardápios para escolas públicas municipais: reflexão e ilustração desse processo em duas capitais brasileiras. Revista de Nutrição, Campinas, v. 25, n. 3, p. 363-372, 2012. 
GOMES JÚNIOR, N. N. G. Segurança alimentar e nutricional como princípio orientador de políticas públicas no marco das necessidades humanas básicas. 2007. Tese (Doutorado em Política Social) - Instituto de Ciências Humanas, Universidade de Brasília, Brasília, DF, 2007.

LIMA, T. L. B. O mercado institucional do Programa Nacional de Alimentação Escolar (PNAE) em Patos de Minas: o processo de implementação e representações sociais na agricultura familiar. 2018. Dissertação (Mestrado em Extensão Rural) Pós-Graduação em Extensão Rural, Universidade Federal de Viçosa, Viçosa, 2018.

MACEDO, D. C.; TEXEIRA, E. M. B.; JÊRONIMO, M. et al. A construção da política de Segurança Alimentar e Nutricional no Brasil. Revista Simbio-Logias, São Paulo, v. 2, n. 1, p. 31-46, 2009.

MALUF, R. S. J. Segurança alimentar e nutricional. Petrópolis: Vozes, 2007.

MARFIL, A. O sabor da agroecologia na alimentação escolar. [S. l.: s. n.], 2014. (Apostila módulo I e II Alimentos agroecológicos: saúde da terra, do alimento e do corpo; módulo III e IV Alimentos agroecológicos: soberania e segurança alimentar).

MORGAN, K.; SONNINO, R. The school food revolution: public food and the challenge of sustainable development. London: Earthscan, 2008.

MOSSMANN, M. P.; TEO, C. R. P. A.; BUSATO, M. A. et al. Interface Between Family Farming and School Feeding: barriers and coping mechanisms from the perspective of different social actors in Southern Brazil. Revista Economia e Sociologia Rural, Brasília, DF, v. 55, n. 2, p. 325-342, 2017.

PEREZ-CASSARINO, J.; MICHELATO, A.; TRICHES, R. et al. A promoção da Soberania e Segurança Alimentar e Nutricional (SSAN) por meio do mercado institucional: a experiência brasileira. In: BEZERRA, I.; PEREZ-CASSARINO, J. (org.). Soberania Alimentar (SOBAL) e Segurança Alimentar Nutricional (SAN): na América Latina e Caribe. Curitiba: Ed. UFPR, 2016. p. 223-246.

PEREZ-CASSARINO, J.; FERREIRA, A. D. D.; MAYER, P. H. Agricultura, campesinato e sistemas agroalimentares: uma proposta de abordagem para a transição agroecológica. Revista Cronos, Natal, v. 14, n. 2, p. 129-152, 2013.

PETTAN, K.; MEDAETS, J. P. (org.). Comercialização na agricultura familiar. Botucatu: Instituto Giramundo Mutuando, 2009.

PIPITONE, M. A. P.; OMETTO, A. M. H.; SILVA, M. V. et al. Atuação dos conselhos municipais de alimentação escolar na gestão do programa nacional de alimentação escola. Revista de Nutrição, Campinas, v. 16, n. 2, p. 143-154, 2003. 
REINACH, S.; CORÁ, M. A. J.; BONDUKI, M. R. P. C. A inclusão da agricultura familiar nas chamadas públicas para compra de alimentos. In: ENCONTRO DA ANPAD, 36., 2012, Rio de Janeiro. Anais [...]. Rio de Janeiro: EnANPAD, 2012. p. 1-15.

RIGON, S. A.; BÓGUS, C. M. A Segurança alimentar e nutricional no Brasil: das concepções norteadoras ao início dos processos de consolidação. In: BEZERRA, I.; PEREZ-CASSARINO, J. (org.). Soberania Alimentar (SOBAL) e Segurança Alimentar Nutricional (SAN): na América Latina e Caribe. Curitiba: Ed. UFPR, 2016. p. 31-54.

SANTANA, A. R.; LETÃO, C. A. T.; NUNES, D. A. et al. Manual de instruções para aquisição de alimentos da agricultura familiar para a alimentação escolar. 3. ed. Palmas: Secretaria do Estado da Educação Palmas, 2015.

SANTOS, H. C. M.; FERNANDES, N. M.; MORENO, M. T. et al. Manual de orientação de cardápios especiais. São Paulo: Secretaria de Estado da Educação, 2015.

SEBRAE. Agricultura familiar: um bom negócio para o desenvolvimento local. Brasília, DF: Sebrae, 2014. (Edição para gestores públicos).

SEBRAE. Programa Nacional de Alimentação Escolar. Vendendo para as escolas: cartilha do produtor João Pessoa: Usina Brasilis, [2---].

SILVA, M. G.; DIAS, M. M.; AMORIM JÚNIOR P. C. G. Mudanças organizacionais em empreendimentos de agricultura familiar a partir do acesso ao programa nacional de alimentação escolar. Revista de Economia e Sociologia Rural, Piracicaba, v. 53, n. 2, p. 289-304, 2015.

SISAN. Sistema Nacional de Segurança Alimentar e Nutricional. SISAN, [s. l.], 10 abr. 2010.

SOARES. P. Análise do programa de aquisição de alimentos na alimentação escolar em um município de Santa Catarina. 2011. Dissertação (Mestrado em Nutrição), Centro de Ciências da Saúde, Universidade Federal de Santa Catarina, Florianópolis, 2011.

SOUSA, A. A.; SILVA, A. P. F.; AZEVEDO, E. et al. Cardápios e sustentabilidade: ensaio sobre as diretrizes do Programa Nacional de Alimentação Escolar. Revista de Nutrição, Campinas, v. 28, n. 2, p. 217-229, 2015.

THIOLLENT, M. (org.). Pesquisa-ação e projeto cooperativo na perspectiva de Henri Desroche. São Carlos: EdUFSCar, 2006. 
TRICHES, R. M.; ALMEIDA, A. P. S.; MENEZES, M. A. et al. A aquisição de produtos da agricultura familiar para o programa de alimentação escolar em dois municípios brasileiros. In: ENCONTRO DA REDE DE ESTUDOS RURAIS, 4., 2010, Curitiba. Anais [...]. Curitiba: Encontro da Rede de Estudos Rurais, 2010.

TRICHES, R. M. Promoção do consumo alimentar sustentável no contexto da alimentação escolar. Trabalho, Educação e Saúde, Rio de Janeiro, v. 13, n. 3, p. 757-771, 2015.

TRICHES, R. M.; BACARRIN, J. G. Interações entre alimentação escolar e agricultura familiar para o desenvolvimento local. In: TEO, C. R. A.; TRICHES, R. M. (org.). Alimentação escolar: construindo interfaces entre saúde, educação e desenvolvimento. Chapecó: Argos, 2016. p. 89-109.

TRICHES, R. M.; SCHNEIDER, S. Alimentação escolar e agricultura familiar: reconectando o consumo à produção. Saúde e Sociedade, São Paulo, v. 19, n. 4, p. 933-945, 2010.

TRICHES, R. M.; SCHNEIDER, S. Desestruturar para construir: interfaces para agricultura familiar acessar o Programa de alimentação escolar. Estudos Sociedade e Agricultura, Rio de Janeiro, v. 20, n. 1, p. 66-106, 2012.

TURPIN, M. E. A alimentação escolar como fator de desenvolvimento local por meio do apoio aos agricultores familiares. Segurança Alimentar e Nutricional, Campinas, v. 16, n. 2, p. 20-42, 2009. 